\title{
Culprit-only versus staged complete revascularization for patients with ST- segment elevation myocardial infarction and Multivessel disease: a retrospective cohort study
}

\author{
Tongtong Yu, Yuanyuan Dong, Jiahe Zhu, Chunyang Tian, Zhijun Sun and Zhaoqing Sun ${ }^{*}$
}

\begin{abstract}
Background: Multivessel disease (MVD) is common in patients with ST-segment elevation myocardial infarction (STEMI), but optimal treatment management remains undetermined.

Methods: In this retrospective cohort study, 602 consecutive STEMI patients with MVD were enrolled between January 1, 2010 and October 1, 2014. Three hundred and eighty-two patients underwent culprit-only revascularization and 220 underwent staged complete revascularization. Primary end points were a composite of cardiac mortality or nonfatal reinfarction.

Results: The mean duration of follow-up was 35 months (12-71 months). Following multivariate analysis, staged complete revascularization was associated with a lower rate of the composite of cardiac mortality or nonfatal reinfarction [HR: 0.430, $95 \% \mathrm{Cl}: 0.197-0.940, P=0.034]$ and unplanned repeat revascularization [HR: 0.343, $95 \%$ Cl: $0.166-0.708, P=0.004]$ compared with culprit-only revascularization.
\end{abstract}

Conclusions: Compared with culprit-only revascularization, staged complete revascularization significantly reduced the rate of the composite of cardiac mortality or nonfatal reinfarction, and the need for unplanned repeat revascularization.

Keywords: Multivessel disease, Revascularization, ST-segment elevation myocardial infarction

\section{Background}

Primary percutaneous coronary intervention (P-PCI) of the culprit artery is widely used in patients with ST-segment elevation myocardial infarction (STEMI). Approximately $50 \%$ of STEMI patients have multivessel disease (MVD) $[1,2]$. Non-culprit lesions are not just "bystanders", as a pathophysiological inflammation process in acute myocardial infarction could cause plaque instability $[3,4]$. Previous research has also shown that STEMI patients with MVD have higher mortality rates and a greater incidence of nonfatal reinfarction than those without MVD [1, 2]. However, the optimal management of STEMI patients with MVD remains undetermined [5-7]. Although a number of randomized controlled trials (RCTs) [8-11], including the PRAMI [9], CVLPRIT [10] and DANAMI-3-PRIMULTI [11] trials, have indicated the clear benefits of complete PCI, other RCTs [12-14], including the PRAGUE-13 trial [12], found no difference between complete and culpritonly revascularization in STEMI patients with MVD. Furthermore, observational studies [15-21] and meta-analyses [22-24] also demonstrated conflicting results.

The present study aimed to determine the benefits and safety of staged complete revascularization in STEMI patients with MVD undergoing P-PCI.

* Correspondence: sunzhaoqing@vip.163.com

Department of Cardiology, Shengjing Hospital of China Medical University,

Shenyang, Liaoning, People's Republic of China

(c) 2016 The Author(s). Open Access This article is distributed under the terms of the Creative Commons Attribution 4.0 International License (http://creativecommons.org/licenses/by/4.0/), which permits unrestricted use, distribution, and reproduction in any medium, provided you give appropriate credit to the original author(s) and the source, provide a link to the Creative Commons license, and indicate if changes were made. The Creative Commons Public Domain Dedication waiver (http://creativecommons.org/publicdomain/zero/1.0/) applies to the data made available in this article, unless otherwise stated. 


\section{Methods}

\section{Study design and setting}

This was a retrospective cohort study, and included consecutive STEMI patients who were hospitalized and underwent PCI at Shengjing Hospital of China Medical University (Shenyang, China) between January 1, 2010 and October 31, 2014. Six hundred and two consecutive cases were selected in this large-scale hospital in Northeast China. Firstly, the investigators identified all consecutive PCI patients from PACS (Picture Archiving and Communication Systems) of the interventional imaging data and assigned each case a unique study ID. The investigators then abstracted comprehensive clinical data and procedural data using electronic medical records. Abstracted elements included patient demographic characteristics, past cardiac and noncardiac history, patient clinical characteristics on hospital admission, laboratory measurements, procedure-related complications and use of cardiac medications during the index hospitalization and at discharge. Killip classification was introduced [5]. All venous blood samples were obtained on admission and tested using autoanalyzers in the core laboratory of Shengjing Hospital and standard techniques. Left ventricular ejection fraction (LVEF) was determined by echocardiography during hospitalization. Procedural data from surgical records in PCI cases were completed by operators. Angiographic variables were estimated visually or by a quantitative computer analysis system. Thrombolysis In Myocardial Infarction (TIMI) flow grade was determined as defined previously [25]. Clinical follow-up was assessed in October 2015 by hospital visits or phone interviews with the patient's general practitioner/cardiologist, the patient or his/her family. All events were obtained from the patients' medical records. If these data were unavailable, statuses were ascertained by a telephone call to the patient's referring hospital physician. All events were adjudicated and classified by two cardiologists.

\section{Participants and procedures}

We identified 1056 STEMI patients treated with P-PCI. Patients who were eligible for P-PCI met the following criteria: (1) chest pain present less than $12 \mathrm{~h}$ from onset of pain to time of catheterization, (2) significant STsegment elevation (at least $0.1 \mathrm{mV}$ in two or more standard leads or at least $0.2 \mathrm{mV}$ in two or more contiguous precordial leads) or a new left bundle branch block. After confirmation of STEMI, P-PCI was immediately undertaken according to current guideline recommendations and operators' routine practice. Operators decided on the use of aspiration thrombectomy, heparin, or glycoprotein IIb/IIIa inhibitor. The culprit artery was determined using ECG, echocardiography and angiographic findings by each operator. For inclusion in the present study, patients had to have MVD, which was defined as the presence of angiographic diameter stenosis of $50 \%$ or greater in at least one non-culprit major epicardial coronary artery or its major branches (with diameter $\geq 2 \mathrm{~mm}$ ). Exclusion criteria included (1) single vessel disease, (2) cardiogenic shock, (3) any type of stent thrombosis, (4) previous coronary artery bypass grafting (CABG), (5) unsuitable for treatment with P-PCI, (6) chronic total occlusion as the only significant non-culprit lesion, (7) non-culprit lesion in coronary artery branches $2 \mathrm{~mm}$ or smaller in diameter. The study population was subdivided into (1) the culprit-only revascularization group (CR group), in which only the culprit lesion received PCI during the index catheterization or hospitalization; (2) the staged complete revascularization group (SR group), in which, after culprit lesion PCI, a planned additional non-culprit lesion PCI was performed during the index hospitalization, or within 1 month after discharge, regardless of symptoms or evidence of ischemia. Periprocedural and postprocedural anti-platelet treatments and other cardiovascular medications were administered in accordance with current guidelines $[5,7]$.

\section{Clinical end points}

The primary end point was a composite of cardiac mortality or nonfatal reinfarction. Secondary end points were all-cause mortality, cardiac mortality, nonfatal reinfarction and unplanned repeat revascularization, including any unplanned repeat PCI or surgical bypass of target or non-target vessels. The safety end points were periprocedure-related complications, including BARC 3 or 5 bleeding, contrast-induced nephropathy, stroke, and acute or subacute stent thrombosis during the index hospitalization. Stroke was defined as an acute event of non-hemorrhagic cerebrovascular origin causing focal or global neurologic dysfunction lasting $>24 \mathrm{~h}$, which was confirmed by both clinical and radiographic criteria. Contrast-induced nephropathy was defined as an increase in serum creatinine concentration $\geq 0.5 \mathrm{mg} / \mathrm{dl} \quad(44.2$ $\mathrm{mmol} / \mathrm{l}$ ) or $\geq 25 \%$ above baseline $72 \mathrm{~h}$ after exposure to the contrast medium. All other end points were defined by standardized definitions [26, 27]. This study complies with the Declaration of Helsinki, and Shengjing Hospital of China Medical University Research Ethics Committee approved the research protocol. Written informed consent was formally obtained from all participants.

\section{Statistical analysis}

Quantitative variables with normal distribution were represented as mean \pm standard deviation (SD) and compared with the independent samples t-test. Quantitative variables without normal distribution were represented as median [interquartile range, IQR] and compared with the Mann-Whitney U-test. Normal distribution was 
assessed by the one-sample Kolmogorov-Smirnov Test. Categorical variables were represented as counts and proportions (\%) and compared using the chi-square test. Event-free survival was estimated in the two groups from Kaplan-Meier curves and compared using the Log-Rank Test. Cox proportional-hazards regression modeling was used to analyze the effects of variables on event-free survival. Variables in Table 1 with $P \leq 0.1$ at the univariate analysis were "entered" into the model (Table 3). These variables included age, gender, current smoker, and previous MI. Results were reported as hazard ratios (HRs) with associated $95 \%$ confidence intervals (CIs). All tests were two-sided, and the statistical significance was defined as $P<0.05$. All statistical analyses were performed using SPSS version 19 (SPSS Inc., Chicago, Illinois, USA).

\section{Results}

\section{Participants}

Between January 1, 2010 and October 1, 2014, a total of 1,056 patients were treated with P-PCI for STEMI in our center. Figure 1 represents the flowchart for patient selection. The final study cohort consisted of 602 patients, of whom $382(63.5 \%)$ received culprit-only revascularization and $220(36.5 \%)$ received staged complete revascularization. For the SR group, the timing of nonculprit lesion PCI was during the index hospitalization

Table 1 Demographics and baseline clinical characteristics, means $\pm S D$, or $N(\%)$

\begin{tabular}{llll}
\hline & $\mathrm{CR}, n=382$ & $\mathrm{SR}, n=220$ & $P$ \\
\hline Age, yrs & $64.6 \pm 12.0$ & $62.7 \pm 11.5$ & 0.052 \\
Male & $257(67.3)$ & $164(74.5)$ & 0.061 \\
Medical history & & & \\
Diabetes & $101(26.4)$ & $70(31.8)$ & 0.159 \\
Hypertension & $194(50.8)$ & $120(54.5)$ & 0.374 \\
Hypercholesterolemia & $100(26.2)$ & $56(25.5)$ & 0.845 \\
Current smoker & $194(50.8)$ & $128(58.2)$ & 0.080 \\
Previous PCl & $14(3.7)$ & $10(4.5)$ & 0.595 \\
Previous Ml & $13(3.4)$ & $14(6.4)$ & 0.091 \\
Killip class II/II on admission & $27(7.1)$ & $13(5.9)$ & 0.582 \\
Systolic blood pressure on & $128.2 \pm 22.0$ & $129.9 \pm 24.0$ & 0.392 \\
admission, mmHg & & & \\
Heart rate on admission, bpm & $77.3 \pm 16.8$ & $77.8 \pm 14.5$ & 0.703 \\
LVEF, \% & $54.0 \pm 9.1$ & $53.6 \pm 9.1$ & 0.662 \\
Symptom to balloon time, $\mathrm{h}$ & $6(4,9)$ & $6(3,9)$ & 0.851 \\
Anterior Ml & $165(43.2)$ & $103(46.8)$ & 0.389 \\
Three-vessel disease & $160(41.9)$ & $106(48.2)$ & 0.134 \\
Intra-aortic Balloon Pump & $31(8.1)$ & $17(7.7)$ & 0.866 \\
\hline MI myocardal infarction, bpm beats & & &
\end{tabular}

MI myocardial infarction, bpm beats per minute, $h$ hour using a staged procedure $(n=208)$ and after index hospitalization but within 1 month $(n=12)$.

\section{Basic characteristics}

Clinical characteristics in the two groups were generally similar and are shown in Table 1. Periprocedural details and discharge medication are shown in Table 2. Patients in the SR group had more stents and longer total stent length. Discharge medication was similar between the two groups (Table 2).

\section{Clinical Outcome}

All patients were followed for a mean duration of 35 months (12-71 months). The length of follow-up in the CR group was 34 months (12-69 months), and was 36 months (12-71 months) in the SR group. During the follow-up period, 31 events of cardiac mortality/nonfatal myocardial reinfarction events, 17 events of cardiac mortality, 14 events of nonfatal myocardial reinfarction, 19 events of all-cause mortality, and 42 events of unplanned repeat revascularization were observed in the CR group; 8 events of cardiac mortality/nonfatal myocardial reinfarction, 4 events of cardiac mortality, 4 events of nonfatal myocardial reinfarction, 5 events of all-cause mortality, and 9 events of unplanned repeat revascularization were observed in the SR group. The composite of cardiac mortality or nonfatal reinfarction was significantly lower in the SR group compared with the CR group [HR: $0.427,95 \%$ CI: 0.196-0.929, $P=0.032$ ], and unplanned repeat revascularization showed a similar trend [HR: 0.349, 95 \% CI: 0.170-0.717, $P=0.004$ ] (Fig. 2; Table 3). After adjusting for covariates (Model 1), the SR group was still associated with a lower rate of the composite of cardiac mortality or nonfatal reinfarction [HR: 0.430, 95 \% CI: 0.197-0.940, $P=0.034]$ and unplanned repeat revascularization [HR: $0.343,95 \%$ CI: $0.166-$ $0.708, P=0.004$ ] compared with the CR group (Table 3 ). There were no statistically significant differences in the other endpoints between the two groups (Table 3). Periprocedure-related complications were not significantly different (Table 4).

\section{Discussion}

The present study determined the effects of different treatment strategies on STEMI patients with MVD in a real-world clinical setting. The main findings were as follows: (1) staged complete revascularization significantly reduced not only the rate of the composite of cardiac mortality or nonfatal reinfarction, but also the need for unplanned repeat revascularization; (2) no significant differences in all-cause mortality, cardiac mortality or nonfatal reinfarction were observed between the treatment strategies; (3) 


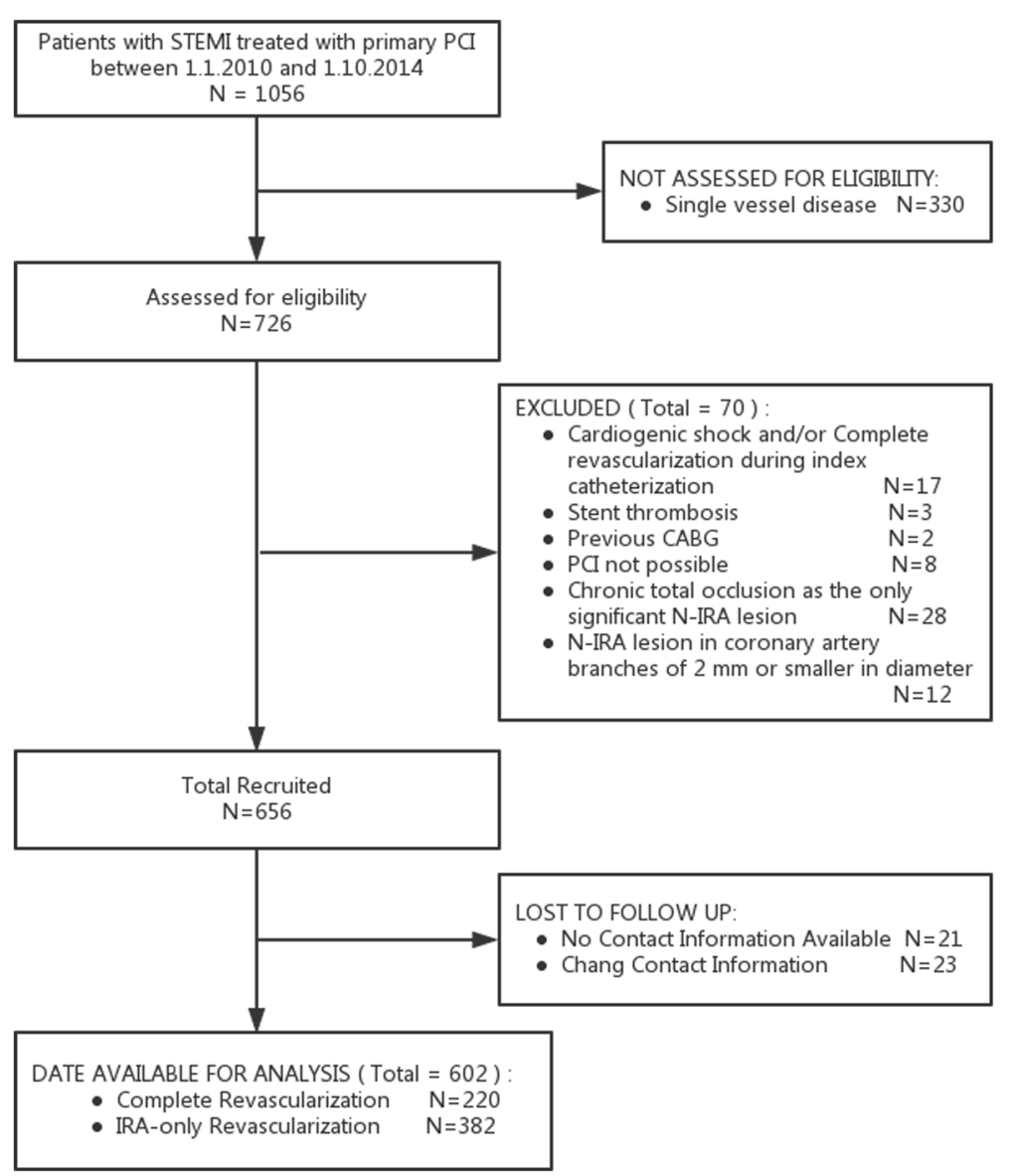

Fig. 1 Flow diagram of participant selection. 330 with single vessel disease, 70 with other exclusion criteria, and 44 without follow-up were excluded. The final study cohort consisted of 602 patients, of whom 382 received culprit-only revascularization and 220 received staged complete revascularization. STEMI, ST-segment elevation myocardial infarction; PCI, percutaneous coronary intervention; CABG, coronary artery bypass grafting; N-IRA, non-Infarct-Related Artery

staged complete revascularization did not significantly increase periprocedure-related complications.

Toyota et al. analyzed 1311 STEMI patients with MVD undergoing P-PCI from the CREDO-Kyoto AMI Registry in Japan (681 in the staged PCI group versus 630 in the culprit-only PCI group), and reported that staged PCI was associated with a lower 5-year composite of cardiac mortality and myocardial infarction compared with culprit-only PCI [HR: 0.67, $95 \%$ CI: $0.44-0.99, P=$ 0.045] [19]. Our findings also showed a lower composite of cardiac mortality and nonfatal reinfarction in the SR group. A similar conclusion was found in the CvLPRIT and DANAMI-3-PRIMULTI trials [10, 11]. However, no studies have found significant differences in cardiac mortality $[8-12,19]$ between the treatment groups. Furthermore, most studies [8-12, 17, 19, 20] found no significant differences in nonfatal reinfarction, except for the PRAMI trial [9] and a recent meta-analysis [23]. Our study also failed to find significant differences in cardiac mortality and nonfatal reinfarction between the two groups. It was demonstrated that staged complete revascularization significantly reduced the need for unplanned repeat revascularization; however, the Japanese study [19] and CvLPRIT trial [10] found no significant differences, and the proportion of patients with three-vessel disease may have played an important role. There was a higher proportion of three-vessel disease in the CR group in our study than in the other two previous studies. In other words, the higher the proportion of three-vessel disease, the higher the proportion of ischemia-driven unplanned repeat revascularizations. Meta-analyses have also confirmed that multivessel PCI will reduce the need for repeat revascularization [22-24]. Different to other studies [17-19], our study found no significant differences in all-cause mortality. It is possible that the follow-up duration in our study was too short to detect significant differences in allcause mortality: 3-year follow-up in our study, 
Table 2 Periprocedural details and discharge medication, median (IQR), or $N(\%)$

\begin{tabular}{|c|c|c|c|}
\hline & $\mathrm{CR}, n=382$ & $\mathrm{SR}, n=220$ & $P$ \\
\hline \multicolumn{4}{|l|}{ Percutaneous coronary intervention } \\
\hline TIMl flow grade $0 / 1$ on arrival & $288(75.4)$ & $165(75.0)$ & 0.914 \\
\hline TIMI flow grade 3 post-PCI & $375(98.2)$ & $218(99.1)$ & 0.369 \\
\hline Number of stents & $1(1,2)$ & $3(2,4)$ & $<0.001$ \\
\hline Stent type & & & 0.211 \\
\hline No stenting & $9(2.4)$ & $1(0.5)$ & \\
\hline Bare metal & $2(0.5)$ & $1(0.5)$ & \\
\hline Drug-eluting & $371(97.1)$ & $218(99.1)$ & \\
\hline $\begin{array}{l}\text { Total stent length for all lesions } \\
\text { treated, } \mathrm{mm}\end{array}$ & $36(24,57)$ & $79(54,109)$ & $<0.001$ \\
\hline Lesion site in culprit vessel & & & 0.700 \\
\hline Left anterior descending artery & $169(44.2)$ & $95(43.2)$ & \\
\hline Left circumflex artery & $48(12.6)$ & $33(15.0)$ & \\
\hline Right coronary artery & $165(43.2)$ & $92(41.8)$ & \\
\hline Thrombus aspiration catheter used & $55(14.4)$ & $27(12.3)$ & 0.464 \\
\hline Use of glycoprotein IIb/llla inhibitor & $142(37.2)$ & $127(42.3)$ & 0.217 \\
\hline \multicolumn{4}{|l|}{ Medical treatment at discharge } \\
\hline Aspirin & $376(98.4)$ & $217(98.6)$ & 0.840 \\
\hline Clopidogrel & $373(97.6)$ & $213(96.8)$ & 0.544 \\
\hline Ticagrelor & $5(1.3)$ & $5(2.3)$ & 0.373 \\
\hline Statin & $358(93.7)$ & $203(92.3)$ & 0.498 \\
\hline Beta-blockers & $224(58.6)$ & $115(52.1)$ & 0.121 \\
\hline $\begin{array}{l}\text { Angiotensin-converting enzyme } \\
\text { inhibitors/Angiotensin receptor } \\
\text { blockers }\end{array}$ & $224(58.6)$ & $133(60.5)$ & 0.662 \\
\hline Calcium-channel blocker & $24(6.3)$ & $9(4.1)$ & 0.255 \\
\hline Nitrate & $39(10.2)$ & $16(7.3)$ & 0.228 \\
\hline Nicorandil & $20(5.2)$ & $6(2.7)$ & 0.145 \\
\hline
\end{tabular}

compared with 5-year and 7-year follow-up in the other two studies $[18,19]$. In addition, the sample size in our study was relatively small, 602 individuals compared with 8822 and 1311 in the other two studies [18, 19]. Accordingly, adequately powered randomized studies should be performed to obtain meaningful conclusions, such as in the COMPLETE trial (ClinicalTrials.gov NCT01740479).

The safety concerns regarding complete revascularization include the risk of procedural complications, longer procedural time, contrast nephropathy, and stent thrombosis which may increase in a prothrombotic and proinflammatory state in the presence of STEMI. Despite this, our study showed no increase in major bleeding, contrast-induced nephropathy, stroke, acute or subacute stent thrombosis. This was consistent with previous studies $[8,10-12,19]$.
There are still several problems related to the treatment of STEMI. First, is staged complete revascularization better than "one-time" complete revascularization? While analysis from the HORIZONS-AMI trial preferred staged complete revascularization [15], other studies found "one-time" complete revascularization safe and effective [20, 21]. Second, what is the appropriate timing of staged revascularization? Different studies had different time cut-off points; however, no study could confirm a favored time cut-off point. Third, should fractional flow reserve (FFR) or a non-invasive physiological stress test be used to determine indications for staged revascularization in addition to angiography? FFR measurements of non-culprit lesions could be performed immediately [28] or several days or weeks [7] after treatment of the culprit vessel. To date, studies with FFR as the reference [11, 13, 14] did not have clearer conclusions than those without FFR as the reference [8-10]. The COMPARE ACUTE trial (ClinicalTrials.gov NCT01399736), an ongoing prospective randomized study comparing a FFR-guided multivessel PCI undertaken during primary PCI of the culprit vessel only, may help us to define the role of FFR in STEMI patients with MVD. Fourth, do the benefits extend to nonculprit stenoses of less than $70 \%$ or $50 \%$ ? The level of non-culprit stenosis at which the risks of PCI surpass the benefits is still uncertain. In addition to FFR, intracoronary imaging such as an intravascular ultrasound study (IVUS) and optical coherence tomography (OCT) could be useful tools for non-culprit lesion revascularization. IVUS and OCT could help us describe in vivo the pathological morphology of plaque associated with an impaired myocardial blush and slow flow leading to a worse prognosis [29]. As for the use of IVUS and OCT, a per-patient tailored therapy may be achieved.

\section{Limitations}

This study had several limitations. First, the study was retrospective and observational, thus potential confounders and selection bias could not be completely adjusted. Second, this was a single center study. Third, the significance of non-culprit lesions was assessed only on angiography, and ischemia tests such as FFR were absent. Fourth, the long symptom to balloon time in this study may have had an impact on the study results, as analysis of the HORIZONS-AMI trial results suggested that a delay in mechanical reperfusion therapy during STEMI is associated with greater injury to the microcirculation [30], and another study showed that a symptom-onset-to-balloon time $>4 \mathrm{~h}$ was an independent predictor of one-year mortality [31]. Finally, the incidence of the primary composite end-point was quite low during the follow-up period. The low number of events may be a limitation in the overall interpretation of the study results. 

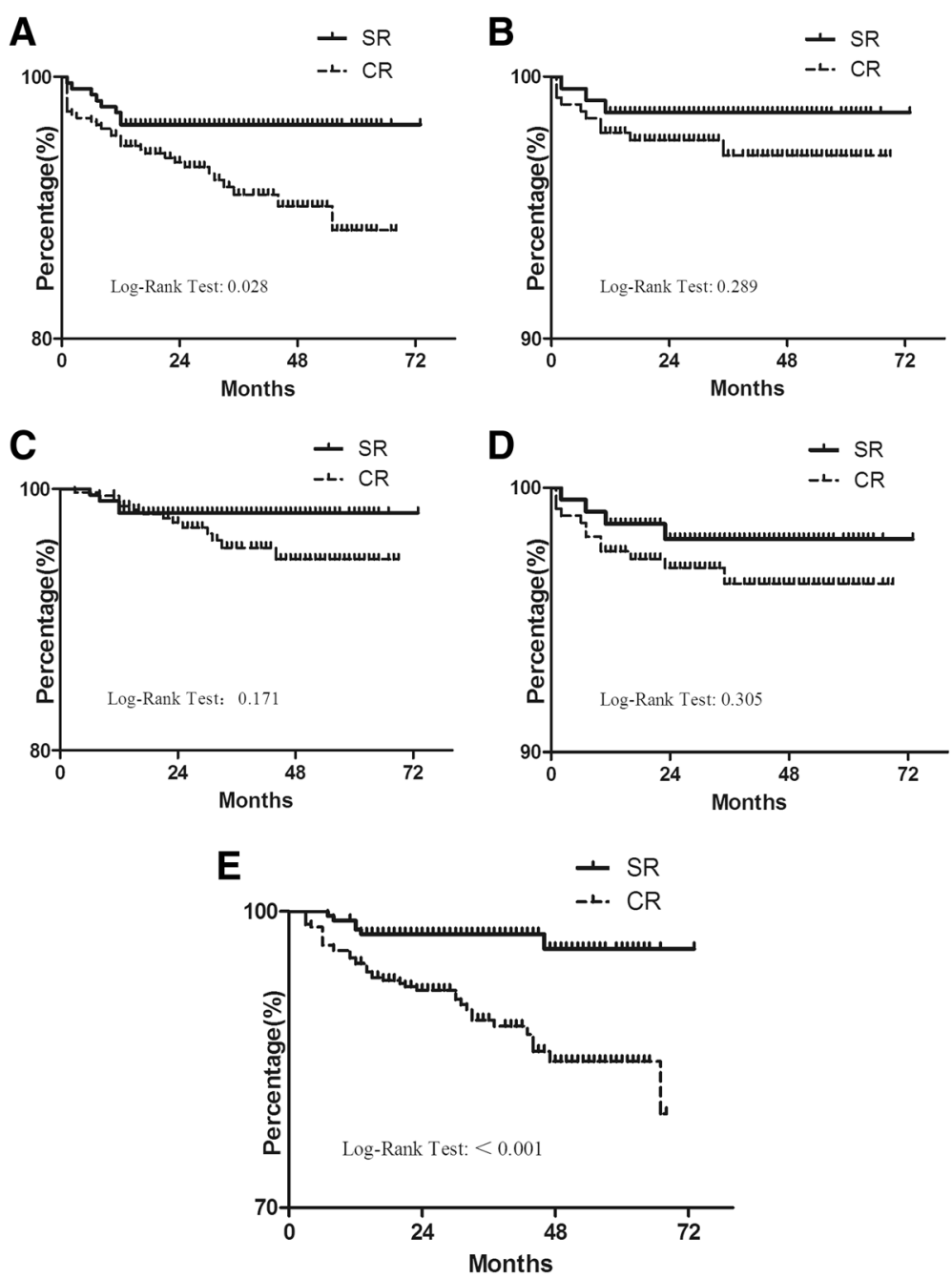

Fig. 2 Kaplan-Meier survival curves free from (a) cardiac mortality/nonfatal reinfarction, (b) cardiac mortality, (c) nonfatal reinfarction, (d) all-cause mortality, (e) unplanned repeat revascularization according to the different groups. SR, staged complete revascularization group; CR, culprit-only revascularization group

Table 3 Univariate and multivariate analysis of the effects of different treatment strategies at follow-Up, N (\%)

\begin{tabular}{|c|c|c|c|c|c|c|}
\hline & \multicolumn{2}{|c|}{ No. patients with event } & \multicolumn{2}{|l|}{ Univariate analysis } & \multicolumn{2}{|l|}{ Multivariate analysis* } \\
\hline & $C R$ & SR & $\mathrm{HR}(95 \% \mathrm{Cl})$ & $P$ & $\mathrm{HR}(95 \% \mathrm{Cl})$ & $P$ \\
\hline \multicolumn{7}{|l|}{ Primary end points } \\
\hline Cardiac mortality/Nonfatal reinfarction & $31(8.1)$ & $8(3.6)$ & $0.427(0.196-0.929)$ & 0.032 & $0.430(0.197-0.940)$ & 0.034 \\
\hline \multicolumn{7}{|l|}{ Secondary end points } \\
\hline Cardiac mortality & $17(4.5)$ & $4(1.8)$ & $0.400(0.135-1.190)$ & 0.100 & $0.440(0.147-1.319)$ & 0.143 \\
\hline Nonfatal reinfarction & $14(3.7)$ & $4(1.8)$ & $0.467(0.153-1.418)$ & 0.179 & $0.442(0.143-1.365)$ & 0.156 \\
\hline All-cause mortality & $19(5.0)$ & $5(2.3)$ & $0.442(0.165-1.185)$ & 0.105 & $0.489(0.181-1.321)$ & 0.158 \\
\hline Unplanned repeat revascularization & $42(11.0)$ & $9(4.1)$ & $0.349(0.170-0.717)$ & 0.004 & $0.343(0.166-0.708)$ & 0.004 \\
\hline
\end{tabular}

*Adjusted for age, diabetes, hypertension, Killip class II/III on admission, systolic blood pressure on admission, heart rate on admission, symptom to balloon time, and anterior $\mathrm{Ml}$ 
Table 4 Periprocedure-related complications, N (\%)

\begin{tabular}{llll}
\hline & $C R(n=382)$ & SR $(n=220)$ & $P$ \\
\hline BARC 3 or 5 bleeding & $2(0.5)$ & $4(1.8)$ & 0.124 \\
Contrast-induced nephropathy & $13(3.4)$ & $5(2.3)$ & 0.433 \\
Stroke & $3(0.8)$ & 0 & 0.188 \\
Acute or subacute stent thrombosis & $1(0.3)$ & 0 & 0.448 \\
\hline
\end{tabular}

\section{Conclusions}

In STEMI patients with MVD, staged complete revascularization for angiographically significant non-culprit lesions was associated with a significantly lower composite of cardiac mortality or nonfatal reinfarction and unplanned repeat revascularization.

\begin{abstract}
Abbreviations
bpm: Beats per minute; Cl: Confidence interval; CR: Culprit-only revascularization group; h: Hour; HR: Hazard ratio; LVEF: Left ventricular ejection fraction; MI: Myocardial infarction; MVD: Multivessel disease; PACS: Picture Archiving and Communication Systems; P-PCl: Primary percutaneous coronary intervention; RCT: Randomized controlled trial; SR: Staged complete revascularization group; STEMI: ST-segment elevation myocardial infarction; TIMI: Thrombolysis In Myocardial Infarction
\end{abstract}

\section{Acknowledgements}

No one who contributed towards the article who does not meet the criteria for authorship.

\section{Funding}

This research project was supported by grants from the Social Development Research Program of Liaoning Province (2011225020).

\section{Availability of data and materials}

The dataset supporting the conclusions of this article is included within the article.

\section{Authors' contributions}

ZS conceived and designed the experiments. TY, YD, JZ and CT performed the experiments. TY analyzed the data and wrote the paper. ZS revised the paper. All authors have reviewed and agreed on the contents of this paper.

\section{Competing interests}

The authors declare that they have no competing interests.

\section{Consent for publication}

Not applicable.

\section{Ethics approval and consent to participate}

This study complies with the Declaration of Helsinki, and Shengjing Hospital of China Medical University Research Ethics Committee approved the research protocol. Written informed consent was formally obtained from all participants.

Received: 26 June 2016 Accepted: 28 September 2016

Published online: 06 October 2016

\section{References}

1. Sorajja P, Gersh BJ, Cox DA, McLaughlin MG, Zimetbaum P, Costantini C, et al. Impact of multivessel disease on reperfusion success and clinical outcomes in patients undergoing primary percutaneous coronary intervention for acute myocardial infarction. Eur Heart J. 2007;28(14):1709-16.

2. Park DW, Clare RM, Schulte PJ, Pieper KS, Shaw LK, Califf RM, et al. Extent, location, and clinical significance of non-infarct-related coronary artery disease among patients with ST-elevation myocardial infarction. JAMA. 2014;312(19):2019-27.

3. Naghavi M, Libby P, Falk E, Casscells SW, Litovsky S, Rumberger J, et al. From vulnerable plaque to vulnerable patient: a call for new definitions and risk assessment strategies. Circulation. 2003;108(14):1664-72.
4. Kubo T, Imanishi T, Kashiwagi M, Ikejima H, Tsujioka H, Kuroi A, et al. Multiple coronary lesion instability in patients with acute myocardial infarction as determined by optical coherence tomography. Am J Cardiol. 2010;105(3):318-22.

5. O'Gara PT, Kushner FG, Ascheim DD, Casey Jr DE, Chung MK, de Lemos JA, et al. 2013 ACCF/AHA guideline for the management of ST-elevation myocardial infarction: a report of the American College of Cardiology Foundation/American Heart Association Task Force on Practice Guidelines. J Am Coll Cardiol. 2013; 61(4):e78-e140.

6. Levine GN, O'Gara PT, Bates ER, Blankenship JC, Kushner FG, Bailey SR, et al. 2015 ACC/AHA/SCAI Focused Update on Primary Percutaneous Coronary Intervention for Patients With ST-Elevation Myocardial Infarction: An Update of the 2011 ACCF/AHA/SCAI Guideline for Percutaneous Coronary Intervention and the 2013 ACCF/AHA Guideline for the Management of ST-Elevation Myocardial Infarction: A Report of the American College of Cardiology/ American Heart Association Task Force on Clinical Practice Guidelines and the Society for Cardiovascular Angiography and Interventions. J Am Coll Cardiol. 2015. doi: 10.1016/j.jacc.2015.10.005. [Epub ahead of print].

7. Steg PG, James SK, Atar D, Badano LP, Blömstrom-Lundqvist C, Borger MA, et al. ESC Guidelines for the management of acute myocardial infarction in patients presenting with ST-segment elevation. Eur Heart J. 2012;33(20):2569-619.

8. Politi L, Sgura F, Rossi R, Monopoli D, Guerri E, Leuzzi C, et al. A randomised trial of target-vessel versus multi-vessel revascularisation in ST-elevation myocardial infarction: major adverse cardiac events during long-term follow-up. Heart. 2010;96(9):662-7.

9. Wald DS, Morris JK, Wald NJ, Chase AJ, Edwards RJ, Hughes LO, et al; PRAMI Investigators. Randomized trial of preventive angioplasty in myocardial infarction. N Engl J Med. 2013; 369(12):1115-1123

10. Gershlick AH, Khan JN, Kelly DJ, Greenwood JP, Sasikaran T, Curzen N, et al. Randomized trial of complete versus lesion-only revascularization in patients undergoing primary percutaneous coronary intervention for STEMI and multivessel disease: the CVLPRIT trial. J Am Coll Cardiol. 2015;65(10):963-72.

11. Engstrøm T, Kelbæk H, Helqvist S, Høfsten DE, Kløvgaard L, Holmvang L, et al; DANAMI-3_PRIMULTI Investigators. Complete revascularisation versus treatment of the culprit lesion only in patients with ST-segment elevation myocardial infarction and multivessel disease (DANAMI3-PRIMULTI): an open-label, randomised controlled trial. Lancet. 2015; 386(9994):665-671

12. Hlinomaz $\mathrm{O}$. Multivessel coronary disease diagnosed at the time of primary PCI for STEMI: complete revascularization versus conservative strategy, PRAGUE 13 trial. Available at: http://sbhci.org.br/wp-content/uploads/2015/ 05/PRAGUE-13-Trial.pdf.

13. Dambrink JH, Debrauwere JP, van 't Hof AW, Ottervanger JP, Gosselink AT, Hoorntje JC, et al. Non-culprit lesions detected during primary $\mathrm{PCl}$ : treat invasively or follow the guidelines? Eurolntervention. 2010;5(8):968-75.

14. Ghani A, Dambrink JH, van't Hof AW, Ottervanger JP, Gosselink AT, Hoorntje JC. Treatment of non-culprit lesions detected during primary $\mathrm{PCl}$ : long-term follow-up of a randomised clinical trial. Neth Heart J. 2012;20(9):347-53.

15. Kornowski R, Mehran R, Dangas G, Nikolsky E, Assali A, Claessen BE, et al; HORIZONS-AMI Trial Investigators. Prognostic impact of staged versus "one-time" multivessel percutaneous intervention in acute myocardial infarction: analysis from the HORIZONS-AMI (harmonizing outcomes with revascularization and stents in acute myocardial infarction) trial. J Am Coll Cardiol. 2011; 58(7):704-711

16. Manari A, Varani E, Guastaroba P, Menozzi M, Valgimigli M, Menozzi A, et al. Long-term outcome in patients with ST segment elevation myocardial infarction and multivessel disease treated with culprit-only, immediate, or staged multivessel percutaneous revascularization strategies: Insights from the REAL registry. Catheter Cardiovasc Interv. 2014;84(6):912-22.

17. Jensen LO, Terkelsen CJ, Horváth-Puhó E, Tilsted HH, Maeng M, Junker A, et al. Influence of multivessel disease with or without additional revascularization on mortality in patients with ST-segment elevation myocardial infarction. Am Heart J. 2015;170(1):70-8.

18. Lee HW, Hong TJ, Yang MJ, An SG, Oh JH, Choi JH, et al; Korea Acute Myocardial Infarction Registry Investigators. Comparison of infarct-related artery vs multivessel revascularization in ST-segment elevation myocardial infarction with multivessel disease: analysis from Korea Acute Myocardial Infarction Registry. Cardiol J. 2012; 19(3):256-66.

19. Toyota T, Shiomi H, Taniguchi T, Morimoto T, Furukawa $Y$, Nakagawa $Y$, et al; CREDO-Kyoto AMI Registry Investigators. Culprit Vessel-Only vs. Staged Multivessel Percutaneous Coronary Intervention Strategies in Patients With Multivessel Coronary Artery Disease Undergoing Primary Percutaneous Coronary 
Intervention for ST-Segment Elevation Myocardial Infarction. Circ J. 2015. doi: 10. 1253/circj.CJ-15-0493. [Epub ahead of print].

20. Rodrigues G, de Araújo Gonçalves P, Madeira S, Rodrigues R, Borges Santos M, Brito J, et al. Impact of complete revascularization in patients with STelevation myocardial infarction: analysis of a 10-year all-comers prospective registry. Coron Artery Dis. 2015 Dec 18. doi: 10.1097/MCA.0000000000000334. [Epub ahead of print].

21. Jeger R, Jaguszewski M, Nallamothu BN, Lüscher TF, Urban P, Pedrazzini GB, et al ; AMIS Plus Investigators. Acute multivessel revascularization improves 1-year outcome in ST-elevation myocardial infarction: a nationwide study cohort from the AMIS Plus registry. Int J Cardiol. 2014; 172(1):76-81.

22. Bainey KR, Mehta SR, Lai T, Welsh RC. Complete vs culprit-only revascularization for patients with multivessel disease undergoing primary percutaneous coronary intervention for ST-segment elevation myocardial infarction: a systematic review and meta-analysis. Am Heart J. 2014;167(1):1-14. e2.

23. Spencer FA, Sekercioglu N, Prasad M, Lopes LC, Guyatt GH. Culprit vessel versus immediate complete revascularization in patients with ST-segment myocardial infarction-a systematic review. Am Heart J. 2015;170(6):1133-9.

24. Moretti C, D'Ascenzo F, Quadri G, Omedè P, Montefusco A, Taha S, et al. Management of multivessel coronary disease in STEMI patients: a systematic review and meta-analysis. Int J Cardiol. 2015;179:552-7.

25. Sheehan FH, Braunwald E, Canner P, Dodge HT, Gore J, Van Natta P, et al. The effect of intravenous thrombolytic therapy on left ventricular function: a report on tissue-type plasminogen activator and streptokinase from the Thrombolysis in Myocardial Infarction (TIMI Phase I) trial. Circulation. 1987; 75(4):817-29.

26. Mehran R, Rao SV, Bhatt DL, Gibson CM, Caixeta A, Eikelboom J, et al. Standardized bleeding definitions for cardiovascular clinical trials: a consensus report from the Bleeding Academic Research Consortium. Circulation. 2011;123(23):2736-47.

27. Cutlip DE, Windecker S, Mehran R, Boam A, Cohen DJ, van Es GA, et al. Academic Research Consortium. Clinical end points in coronary stent trials: a case for standardized definitions. Circulation. 2007;115(17):2344-51.

28. Ntalianis A, Sels JW, Davidavicius G, Tanaka N, Muller O, Trana C, et al. Fractional flow reserve for the assessment of nonculprit coronary artery stenoses in patients with acute myocardial infarction. JACC Cardiovasc Interv. 2010;3(12):1274-81.

29. Iannaccone M, Vadalà P, D'ascenzo F, Montefusco A, Moretti C, D'amico M, et al. Clinical perspective of optical coherence tomography and intravascular ultrasound in STEMl patients. J Thorac Dis. 2016:8(5):754-6.

30. Prasad A, Gersh BJ, Mehran R, Brodie BR, Brener SJ, Dizon JM, et al. Effect of Ischemia Duration and Door-to-Balloon Time on Myocardial Perfusion in STSegment Elevation Myocardial Infarction: An Analysis From HORIZONS-AMI Trial (Harmonizing Outcomes with Revascularization and Stents in Acute Myocardial Infarction). JACC Cardiovasc Interv. 2015;8(15):1966-74.

31. De Luca G, Suryapranata H, Zijlstra F, van 't Hof AW, Hoorntje JC, Gosselink AT, et al. Symptom-onset-to-balloon time and mortality in patients with acute myocardial infarction treated by primary angioplasty. J Am Coll Cardiol. 2003;42(6):991-7.

\section{Submit your next manuscript to BioMed Central and we will help you at every step:}

- We accept pre-submission inquiries

- Our selector tool helps you to find the most relevant journal

- We provide round the clock customer support

- Convenient online submission

- Thorough peer review

- Inclusion in PubMed and all major indexing services

- Maximum visibility for your research

Submit your manuscript at www.biomedcentral.com/submit

C) Biomed Central 